\title{
Cross-linguistic differences in categorical perception: Comparison of Danish and Norwegian
}

\author{
Byurakn Ishkhanyan \\ School of Communication and Culture, Aarhus University, DK \\ Jens Chr. Schous Vej 2, DK-8000 Aarhus C, Denmark. E-mail: byurakn@cc.au.dk \\ Riccardo Fusaroli \\ School of Communication and Culture and the Interacting Minds Centre, \\ Aarhus University, DK \\ Anders Højen \\ TrygFondens Centre for Child Research, Aarhus University, DK \\ Kristian Tylén \\ School of Communication and Culture and the Interacting Minds Centre, \\ Aarhus University, DK \\ Christer Johansson \\ Department of Linguistic, Literary and Aesthetic Studies, University of Bergen, Norway \\ Morten H. Christiansen \\ School of Communication and Culture and the Interacting Minds Centre, \\ Aarhus University, DK \\ Department of Psychology, Cornell University, Ithaca, NY
}

Corresponding author: Byurakn Ishkhanyan, School of Communication and Culture, Aarhus University, Jens Chr. Schous Vej 2, DK-8000 Aarhus C, Denmark. E-mail: byurakn@cc.au.dk 


\section{Cross-linguistic differences in categorical perception: Comparison of Danish and Norwegian}

\section{Abstract}

Are all languages processed in the same way, or might typological variation cause systematic differences between languages? We explore this question through a cross-linguistic comparison of categorical perception in two closely related languages, Danish and Norwegian. We employ drift diffusion models to reveal cross-linguistic differences in the role of context: Danish - a more phonologically-opaque language - shows equally strong context effects of both near and distal context, while Norwegian shows stronger context effect of near than distal context. We argue that the difference is due to a processing strategy: due to the more transparent sound structure of their language, Norwegians pay more attention to local acoustic information - while Danes, due to the opaque phonology of Danish, seem to use later-occurring contextual information to a larger extent. Indeed, when forcing participants to delay their decision until the full information is available, Norwegians show choice patterns more similar to those of Danes. Our findings highlight the importance of cross-linguistic studies, as even closely related languages like Danish and Norwegian, appear to be processed differently contingent on individual properties of the specific language.

\section{Keywords}

Categorical perception; cross-linguistic studies, spoken word recognition; speech perception; Danish; Norwegian 


\section{Introduction}

The past decade has seen a growing realization that studies of people in Western Educated Industrialized Rich Democratic (WEIRD, Henrich, Heine \& Norenzayan, 2010) countries may not necessarily yield general insights into human psychology that applies universally across all cultures. Within the language sciences, there is now a renewed focus on the ways in which the languages of the world differ from each other (e.g., Evans \& Levinson, 2009), and an increased interest in documenting differences between languages that may be theoretically significant. For example, detailed studies of language input to children growing up in indigenous communities have revealed that although these children receive considerably less input than their WEIRD peers, they nonetheless seem to reach the same language acquisition milestones at approximately the same time in development (e.g., Casillas, Brown \& Levinson, 2019). Other studies have explored whether specific properties of a given language may affect how it is acquired. Along these lines, it has been suggested that the opaque nature of Danish phonology has made this language harder to learn than otherwise comparable neighboring languages (e.g. Norwegian), resulting in delayed vocabulary and past tense acquisition by Danish children (Bleses et al., 2008; Bleses, Basbøll \& Vach, 2011; for a review see Trecca, Tylén, Højen \& Christiansen, submitted). Less research has examined whether differences between languages can also affect how they are processed in adulthood. However, investigations of cross-linguistic variation in speech processing can inform long-standing discussions about whether languages are built, fundamentally, on the same underlying, universal, linguistic processing architecture (e.g., Pinker \& Bloom, 1990) or whether they instead have unique characteristics that are shaped by cultural-historical factors within the constraints of human cognition (e.g., Evans \& Levinson, 2009). In the current study, we therefore 
Cross-linguistic differences in categorical perception

investigate if and how the relative weighting of different kinds of linguistic information in language processing may be affected by language-specific properties.

\section{Bottom-up and top-down processing}

Language processing depends on the integration and weighting of multiple kinds of cues.

We segment and analyze incoming speech streams in a bottom-up manner to identify words and phrases. These bottom-up cues include acoustic-phonetic information (Schiller \& Meyer, 2003), distributional relationships between words (e.g., McCauley \& Christiansen, 2019), and prosodic regularities (e.g., Cutler, Dahan \& Van Donselaar, 1997). But we also attend to contextual cues to facilitate processing in a top-down fashion, given an often underspecified or ambiguous input. Such top-down cues include lexical-semantic information about specific words (e.g., verb restrictions, MacDonald, Pearlmutter \& Seidenberg, 1994), knowledge about the real world (e.g., action-goal relations, Kamide, Altmann \& Haywood, 2003), and pragmatic inferences about speakers' intentions, which are often related to and modulated by the broader discourse context (Nieuwland \& Van Berkum, 2006; Otten \& Van Berkum, 2008; Tylén et al., 2015). While the relative contribution of bottom-up vs. top-down information in language processing has been the subject of longstanding debate (e.g., Bates \& MacWhinney, 1987; Christiansen \& Chater, 2016; Kintsch, 2005; Marslen-Wilson \& Welsh, 1978; Roark, 2001), recent work suggests that top-down processes become especially relevant when the quality of acoustic-phonetic information decreases (e.g., Beretti et al., 2020; Chodroff \& Wilson, 2020; Szostak \& Pitt, 2013; Bushong \& Jaeger, 2017; Borsky, Tuller \& Shapiro, 1998; Gaskell \& Marslen-Wilson, 2001). Motivated by recent evidence from Danish and Norwegian (Ishkhanyan et al., 2019; Trecca et al., 2019), we here explore whether the balance between bottom-up and top-down processes might also be affected by cross-linguistic differences between these two languages. 


\section{Danish and Norwegian}

Danish and Norwegian are two closely related languages with highly similar vocabularies and grammars, and they are largely mutually intelligible (e.g., Gooskens, 2006). Written Danish and the Bokmål form of written Norwegian are also very similar. The two languages have a similar number of consonant phonemes: Norwegian counts range from 18 to 25, depending of dialectal variation, and standard Danish has 18 (Basbøll, 2005; Kristoffersen, 2015). Both languages have a relatively large inventory of vowel phonemes, 18 in Norwegian and 21 in Danish, including vowel length distinctions (Grønnum, 1998; Kristoffersen, 2015). The surface realizations of the Danish phonemes vary greatly, however, with as many as 42 phonetically distinct vowel qualities. In addition, Danish has a remarkably large number of diphthongs, i.e., sounds with two vowel qualities, namely 49 diphthongs against 6 diphthongs in most Norwegian dialects (Grønnum, 1998; 2005, Kristoffersen, 2015). The high number of Danish diphthongs are mostly due to lenition of consonants, which is not extensively present in Norwegian (with the possible exception of a few southwestern dialects, Goblirsch, 2002).

In addition to consonant lenition, syllables tend to be reduced via elision to a larger degree in Danish than in Norwegian, resulting in many words or word sequences sounding ambiguous and thus needing context to disambiguate them (Basbøll, 2005). For example, in Danish but not Norwegian, the three words bad ("bath", noun), bade (to "bathe", verb) and badede ("bathed", verb) are all pronounced in a similar way in casual speech, [bæ:ठָ], with only the duration of the final sound providing a cue to syllabic structure and word identity.

There is evidence that the particular sound properties of Danish affect aspects of language acquisition. For instance, Danish-learning infants have greater difficulty processing speech that is characterized by multiple vocalic sounds in a sequence (more prevalent in Danish than e.g., 
Norwegian) than speech that alternates between consonantal and vocalic speech sounds (Trecca et al., 2018, 2020). However, Danish children seem to catch up later in life (see Trecca et al., submitted, for a review). We propose that this is due to the recruitment of compensatory processes: Danes $^{1}$ might thus develop more fine-grained phonological representations than Norwegians and/or processing strategies more reliant on contextual information. In this study, we investigate a potential compensatory mechanism: whether native adult Danes compensate for the defective bottom-up acoustic cues associated with the sound properties of Danish, by making a greater use of contextual top-down information compared to Norwegians.

\section{Categorical perception in sentence context}

Although the acoustic-phonetic input is variable and noisy, the perception of speech sounds is categorical (Liberman et al., 1957). In running speech, the acoustic-phonetic realization of individual sounds may vary substantially. Still, listeners typically perceive them unambiguously as canonical sounds. For example, when presented with intermediate varieties between $/ \mathrm{b} / \mathrm{and} / \mathrm{p} /$, participants perceive each sound as either a distinct $/ \mathrm{b} /$ or $/ \mathrm{p} /$, and not an intermediate sound. However, perception of intermediate steps in a continuum is subject to phonetic context effects (e.g., Repp \& Liberman, 1987; Petitot, 1988) as well as semantic context effects, which indicate the influence of top-down processing on speech sound perception (Brown-Schmidt \& Toscano, 2017; Connine, Blasko \& Hall, 1991; Bushong \& Jaeger, 2017; McMurray, Tanenhaus \& Aslin, 2009; Szostak \& Pitt, 2013). Thus, to successfully recognize individual words in running speech, ambiguous acoustic-phonetic bottom-up information is integrated with top-down contextual information (e.g., Connine et al., 1991).

\footnotetext{
${ }^{1}$ Here and elsewhere in the article we use the terms "Danes" and "Norwegians" as a shorthand for adult native speakers of Danish and Norwegian, acknowledging that not all Danes and Norwegians are native speakers of Danish and Norwegian.
} 
Cross-linguistic differences in categorical perception

The categorization of the target word is not only a matter of the degree of ambiguity of the acoustic-phonetic input and disambiguating context, but also limitations on auditory memory. The listener needs to maintain the sub-categorical information until the disambiguating contextual information is integrated. However, the ability to maintain such acoustic details is rather limited and the sub-categorical information cannot be maintained indefinitely (Now-or-Never-bottleneck: Christiansen \& Chater, 2016). There is no consensus, though, how long the sub-categorical information can be retained to accommodate integration of a disambiguating context.

To address these two issues - the contextual bias effect and timing strategies - in American English, Connine et al. (1991) presented experimental participants with a five-step [d]-[ $\left.\mathrm{t}^{\mathrm{h}}\right]$ continuum from dent to tent. The words were presented in carrier sentences that were either semantically biased towards dent (After the_ent corroded, they patched it) or tent (After the_ent collapsed, we went home). The authors also manipulated the number of syllables that separated the target word from the disambiguating context. In the NEAR condition, the distance between the target word and the disambiguating word was three syllables, whereas in the FAR condition that distance was six to eight syllables. The results showed that the listeners' perception of intermediate steps was biased by the semantic context. The authors concluded that when the acoustic-phonetic input is ambiguous, listeners tend to rely on top-down inference to a larger extent than when the input is clear. Interestingly, the contextual bias effect diminished in the FAR condition supporting the idea of acoustic memory limitations. The response time data indeed revealed that in the FAR condition most of the time the listeners did not even wait to hear the disambiguating information to make a decision. Based on duration measurements of the stimulus sentences, Connine et al. (1991) concluded that there is a 1-second time window for processing acoustic-phonetic input, after which the information decays. 
Cross-linguistic differences in categorical perception

Subsequent studies have shown that the bias effect can be extended beyond 1-second (e.g. Szostak \& Pitt, 2013; Brown-Schmidt \& Toscano, 2017; \{Citation $\}$ Bushong \& Jaeger, 2017). For example, Szostak \& Pitt (2013) argued that the temporal window, in which acoustic-phonetic information is still available, may vary due to factors like syntactic structure or experience with language use. Bushong \& Jaeger (2017), however, showed that the bias effect may also be due to active strategies: if forced to wait until the contextual information is available, contextual bias will be stronger, whereas in conditions where it is allowed to make a decision prematurely, the contextual bias may be smaller. In fact, the initial decision about the target word based on bottomup information may shift once contextual information becomes available (Brown-Schmidt \& Toscano, 2017), and the bias effect can decrease if the sub-phonemic information is not correlated with the context (Bushong \& Jaeger, 2019). Thus, limitations on phonological memory for maintaining acoustic-phonetic information is not the only factor determining the strength of the contextual bias effect— - task related demands also play a role.

The observation that context integration in speech processing varies with task demands motivates the hypothesis that context integration may also vary across languages contingent on typological properties and their affordances for different processing strategies. In particular, we hypothesize that the more opaque sound structure of Danish might make Danes prone to put more weight on contextual information in categorical perception processes, while Norwegians rely relatively more on the bottom-up acoustic information.

\section{The present study}

Adapting the paradigms used by Connine et al. (1991) and Szostak and Pitt (2013) to Danish and Norwegian, we investigated the possible processing differences in the weighting of bottomup and top-down information across the two languages. We expected that while both Danish and 
Norwegian speakers would rely on context when processing ambiguous acoustic-phonetic input, Danish speakers would weight this information relatively more than Norwegians (Bias x Language interaction). Moreover, since context is hypothesized to have a larger effect for Danish speakers, we would expect the Bias effect present both in the NEAR and FAR conditions in Danish speakers, but to a lesser extent (or even absent) in the FAR condition in Norwegians (Cross-linguistic $\mathrm{x}$ Language three-way interaction).

We conducted two experiments. In Experiment 1, based on the design by Connine et al. (1991), the listeners could respond at any time they wanted after hearing the target word, allowing us to observe potential cross-linguistic differences in processing strategies between Danish and Norwegian speakers. If Norwegian speakers, as hypothesized, rely more on bottom-up information, they would be expected not to wait for the integration of the full sentence context before they respond. By contrast, in Experiment 2, listeners could only respond after the sentence offset (Szostak \& Pitt, 2013). Experiment 2 thus investigates whether the performance of Norwegian speakers becomes more similar to performance of Danish, when they are forced to wait to the sentence offset before they can respond.

Traditionally, categorical perception studies rely on which response is given to investigate contextual bias. However, reaction times have been shown to provide additional insights into the underlying mechanisms affecting choice, thus increasing the sensitivity of the analysis (e.g., Ratcliff \& McKoon, 2008). We used Drift Diffusion Models (DDM, Ratcliff, 1978) integrating response and reaction times in a single model more sensitive to bias effects (see methods for details). For easier comparison with previous research, we also report more typical psychometric curve models based on participants' responses in the Supplementary Materials. 


\section{Experiment 1}

In Experiment 1, we investigated whether the contextual bias effect is larger in Danish than Norwegian, whether Danish speakers maintain sub-categorical information longer than Norwegian speakers (NEAR vs. FAR contrast), and whether Danish speakers tend to wait longer before responding in order to integrate more of the contextual information, compared to Norwegians. While we expected to replicate previous findings (in English) of contextual bias effects across distances and languages, our main hypothesis for Experiment 1 (H1) is that the contextual bias in Danish speakers is stronger and persists longer than in Norwegian speakers. Therefore, we expected that the Bias x Distance interaction described by Connine et al. (1991) and Szostak \& Pitt (2013) would be smaller in Danish than in Norwegian (i.e., a Bias x Distance x Language interaction).

\section{Method}

\section{Participants}

Forty healthy Danish native speakers (female $=26$, age $=18-36$, median $=22, \mathrm{sd}=2.6)$ and 34 healthy Norwegian native speakers $($ female $=13$, age $=19-36$, median $=23$, sd $=3.3$ ) participated in this study. The Danish speakers were recruited at the Cognition and Behavior Lab at Aarhus University, Denmark, and the Norwegian participants were recruited at the Faculty of Humanities at the University of Bergen, Norway. The participants received a monetary compensation (equivalent to ca. 26 USD) for participating in a battery of different experiments. The current categorical perception experiment always occurred as the second test in the battery. All participants were right-handed and reported no history of neurological, psychiatric or 
Cross-linguistic differences in categorical perception

developmental disorders. They all had (corrected to) normal vision and normal hearing. All the participants provided written consent for their participation in the experiment.

\section{Materials}

For each language, Danish and Norwegian, we constructed 16 pairs of carrier sentences, half of which were biased towards the target word sendt (identical in Danish and Norwegian) [English "sent"] and half biased towards toendt in Danish or tent in Norwegian [English "lit/turned on"]. In both languages, the words are minimal pairs, only differing in the onset consonant.

In 8 pairs, the distance between the target and the disambiguating word was one syllable (NEAR condition); in the remaining 8 pairs the distance was 6-7 syllables (FAR condition). Each FAR condition sentence was constructed by adding 2-4 words just before the disambiguating word in a NEAR condition sentence.

Because both syntax and vocabulary of Danish and Norwegian are very similar, it was possible to use highly similar translation equivalents in the two languages. Table 1 shows the structure and biases of the sentences and their English translations. See the Appendix for a full list of the Danish and Norwegian sentences.

Table 1. Example of two sentences with a bias either towards sent (Danish sendt, Norwegian sendt) or towards lit/turned-on (Danish toendt, Norwegian tent).

Bias NEAR condition $\quad$ FAR condition

Sendt

Hun har

en mail. Hun har en imponerende klar mail. 
Cross-linguistic differences in categorical perception

Sent

She has an email. She has an impressively clear email.

Tændt/Tent

Hun har en lampe. Hun har en imponerende klar lampe.

Lit/turned-on

She has a lamp. She has an impressively clear lamp.

Both Danish and Norwegian stimuli were recorded by a native male speaker of the respective languages using professional recording equipment. Several renditions of each sentence were recorded with both the words sendt and teendt/tent. A token of the phrase Hun har teendt/Hun har tent was chosen as carrier sentence for Danish and Norwegian respectively.

Because Danish $\left[t^{\mathrm{s}}\right]$ has a great deal of sibilant frication noise, essentially making it an affricate, an $[\mathrm{s}]-\left[\mathrm{t}^{\mathrm{s}}\right]$ continuum could be generated by manipulation the silent interval, noise duration, and noise rise time. An [s] with a duration of $127 \mathrm{~ms}$ was spliced to the Hun har tcendt token, substituting the $\left[\mathrm{t}^{\mathrm{s}}\right]$ in tændt. Ten copies of this sound file were made, which had the frication noise of $[\mathrm{s}]$ but the silent interval of $\left[\mathrm{t}^{\mathrm{s}}\right]$. To generate the $[\mathrm{s}]-$ end of the continuum, the silent interval of $63 \mathrm{~ms}$ was edited out. To generate the [ $\left[\mathrm{t}^{\mathrm{s}}\right]$-end of the continuum, the first $63 \mathrm{~ms}$ of the frication noise were edited out, resulting in an affricate with a rather abrupt noise onset (rise time set to 2 $\mathrm{ms}$ ) and with a duration of $64 \mathrm{~ms}$. Eight intermediate steps were generated by interpolating between the endpoint stimuli in terms of silent interval duration, frication noise duration and noise rise time, as shown in Table 2. Copies of the audio recordings are available at shorturl.at/krIOT To prevent any start-up clicks or pops in the sentence signal, $100 \mathrm{~ms}$ of silence were inserted in the beginning of each sound file. 
Cross-linguistic differences in categorical perception

Table 2. 10-step Danish $[\mathrm{s}]-\left[\mathrm{t}^{\mathrm{s}}\right]$ and Norwegian $[\mathrm{s}]-\left[\mathrm{t}^{\mathrm{h}}\right]$ continua

\begin{tabular}{|c|c|c|c|c|c|c|c|c|c|c|c|}
\hline & Values & 1 & 2 & 3 & 4 & 5 & 6 & 7 & 8 & 9 & 10 \\
\hline \multirow[t]{3}{*}{ Danish } & Silent interval, ms & 0 & 7 & 14 & 21 & 28 & 35 & 42 & 49 & 56 & 63 \\
\hline & Noise, ms & 127 & 120 & 113 & 106 & 99 & 92 & 85 & 78 & 71 & 64 \\
\hline & Rise time, ms & As is & 18 & 16 & 14 & 12 & 10 & 8 & 6 & 4 & 2 \\
\hline \multirow[t]{4}{*}{ Norwegian } & Silent interval, ms & 0 & 7 & 14 & 21 & 28 & 35 & 42 & 49 & 56 & 63 \\
\hline & Noise, ms & 127 & 120 & 113 & 106 & 99 & 92 & 85 & 78 & 71 & 64 \\
\hline & Rise time, ms & As is & 18 & 16 & 14 & 12 & 10 & 8 & 6 & 4 & 2 \\
\hline & $\mathrm{dB}$ drop & 0 & 1 & 2 & 3 & 4 & 5 & 6 & 7 & 8 & 9 \\
\hline
\end{tabular}

Like Danish $[\mathrm{s}]$ and $\left[\mathrm{t}^{\mathrm{s}}\right]$, the Norwegian $[\mathrm{s}]$ and $\left[\mathrm{t}^{\mathrm{h}}\right]$, differed primarily according to the duration of the frication noise, the rise time of the noise, and the duration of the silent interval between noise offset and onset of the following vowel. However, the Norwegian target words' [s] and $\left[\mathrm{t}^{\mathrm{h}}\right]$ sounds also differed in intensity. Therefore, the Norwegian $[\mathrm{s}]$ and $\left[\mathrm{t}^{\mathrm{h}}\right]$ continuum was generated using a procedure identical to that used for Danish, with the exception of additional 
Cross-linguistic differences in categorical perception

interpolation of intensity between endpoints, see Table 2 . The continua had a clear [s] at one end and a clear $\left[\mathrm{t}^{\mathrm{s}}\right]$ (Danish) or $\left[\mathrm{t}^{\mathrm{h}}\right]$ (Norwegian) at the other end and with eight intermediate steps.

We then piloted the two continua (forced-choice identification) on 11 participants for Danish and 18 for Norwegian. Based on the identification functions, we chose steps 4,5 and 6 as they straddled the mean category boundaries in each language, to maximize potential context effects. These three intermediate steps and the endpoints were used in the experiment. Thus, there were 160 trial sentences in total. The experiment was programmed and carried out in PsychoPy2 v1.90.1. (Peirce \& MacAskill, 2018).

\section{Procedure}

Prior to the experiment, the participants received detailed instructions on the screen in their native languages. They were told to click on the word they thought they heard and they were warned that sometimes this would not be easy. The participants were also instructed that they could use any information in the sentence that may help them to make their decision (similar to Connine et al., 1991; Szostak \& Pitt, 2013). Following the instructions, the participants completed a practice trial before commencing the experiment. The target words sendt and toendt/tent were presented in boxes in the upper left and right corners of the screen while the target sentences were played back through headphones (Figure 1). The participants responded by clicking on the appropriate word with the mouse. There was a pause of $1.5 \mathrm{~s}$ between each trial, during which a blank screen was presented. The 160 stimuli were presented in a pseudorandomized order across four blocks of 40 trials. The first two stimulus items of the experiment contained the endpoints $[\mathrm{s}]$ and $\left[\mathrm{t}^{\mathrm{s}}\right] /\left[\mathrm{t}^{\mathrm{h}}\right]$, respectively, in a congruent context. After each block, the participants had a self-paced short break. The entire experiment took 15 - 20 minutes. Responses and response times (RTs) were recorded 
as dependent variables. RTs were measured from the onset of the target word until the mouseclick.

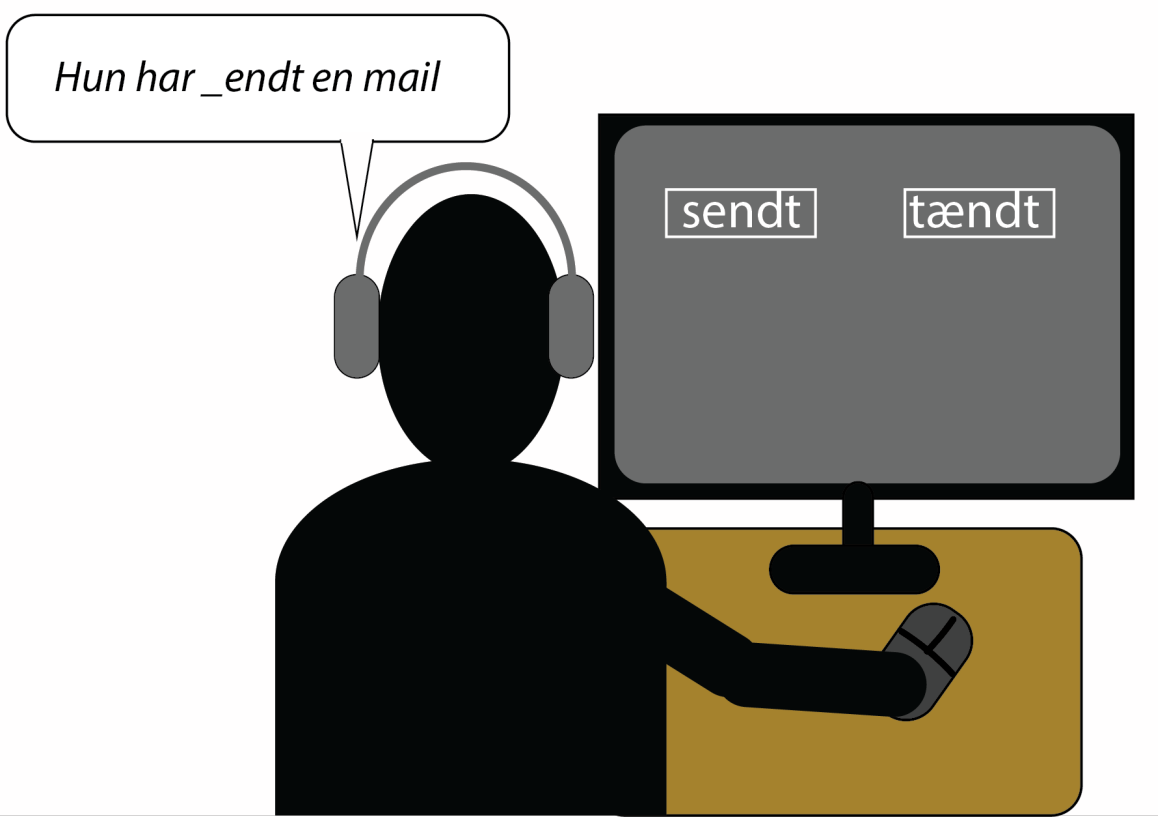

Figure 1: The experimental procedure. The participant heard the stimuli through the headphones and had to choose with the mouse whether they heard sendt or toendt.

\section{Data analysis}

We evaluated participant attention by assessing their "correct" response rates to trials where the stimulus was maximally distinct (the end points) and the context was congruent. We excluded participants who performed at or below chance level in these cases (congruent response $<50 \%$ of the cases). Four Norwegian participants in total were excluded. In addition, we excluded trials with a reaction time more than 3 standard deviations above the mean (that is, slower than 8.008 
seconds). No lower bound was set, given that there were no values 3 standard deviations equal below the mean and no values below $200 \mathrm{~ms}$. We also excluded trials with missing values as responses (i.e., the click was outside the response boxes). This excluded 87 trials $(0.78 \%)$, leaving a total number of 10999 trials.

We modeled participant performance using a Bayesian implementation of the drift diffusion model, which integrates responses and response times (RT) in one model (for a more traditional psychometric curve model relying on a binomial regression, see the Supplementary Materials). When responses are analyzed in isolation, the temporal aspect of the underlying cognitive processes is not taken into account and thus important information may be missed (Ratcliff \& McKoon, 2008). Thus, integrating RTs and responses in a single model provides more fine-grained information about the decision process. Compared to other approaches, the Drift Diffusion Model (DDM) has been shown to be a conceptually sound method for integrating responses and RTs, as it takes into account not only mean RTs but also RT distributions for each alternative choice (Ratcliff, 1978; Stafford et al., 2020). The DDM employs sequential sampling to model cognitive processes underlying decision-making in 2-choice discrimination tasks (Ratcliff \& McKoon, 2008). The model has four parameters: drift rate, boundary separation, bias and non-decision time. Drift rate $(\delta)$ is the average rate of evidence accumulation and is related to the subjective difficulty of the task (Lerche \& Voss, 2016). Thus, higher drift rates indicate that the participants find the task easier and lower drift rates indicate that the participants find it more difficult. Positive drift rate values indicate that evidence accumulates for the upper boundary (in this case, a toendt response). Negative drift rates indicate that the evidence is accumulated towards the lower boundary (in this case, a sendt response). The boundary separation $(\alpha)$ is the amount of evidence necessary to make a decision and is always positive. The boundary separation is generally smaller in "speed" conditions ("respond as fast as you can") and larger in "accuracy" conditions ("respond 
as accurate as you can”) (Ratcliff et al., 2016). The starting point (b) quantifies the presence of an initial bias towards one of the response boundaries, with negative values indicating a bias towards the lower boundary, positive towards the upper boundary, and 0 no bias. Non-decision-time ( $\boldsymbol{\tau})$ is the part of the response time that is not involved in decision making (e.g., the time that precedes evidence accumulation necessary for perceiving the stimuli) (Figure 2).

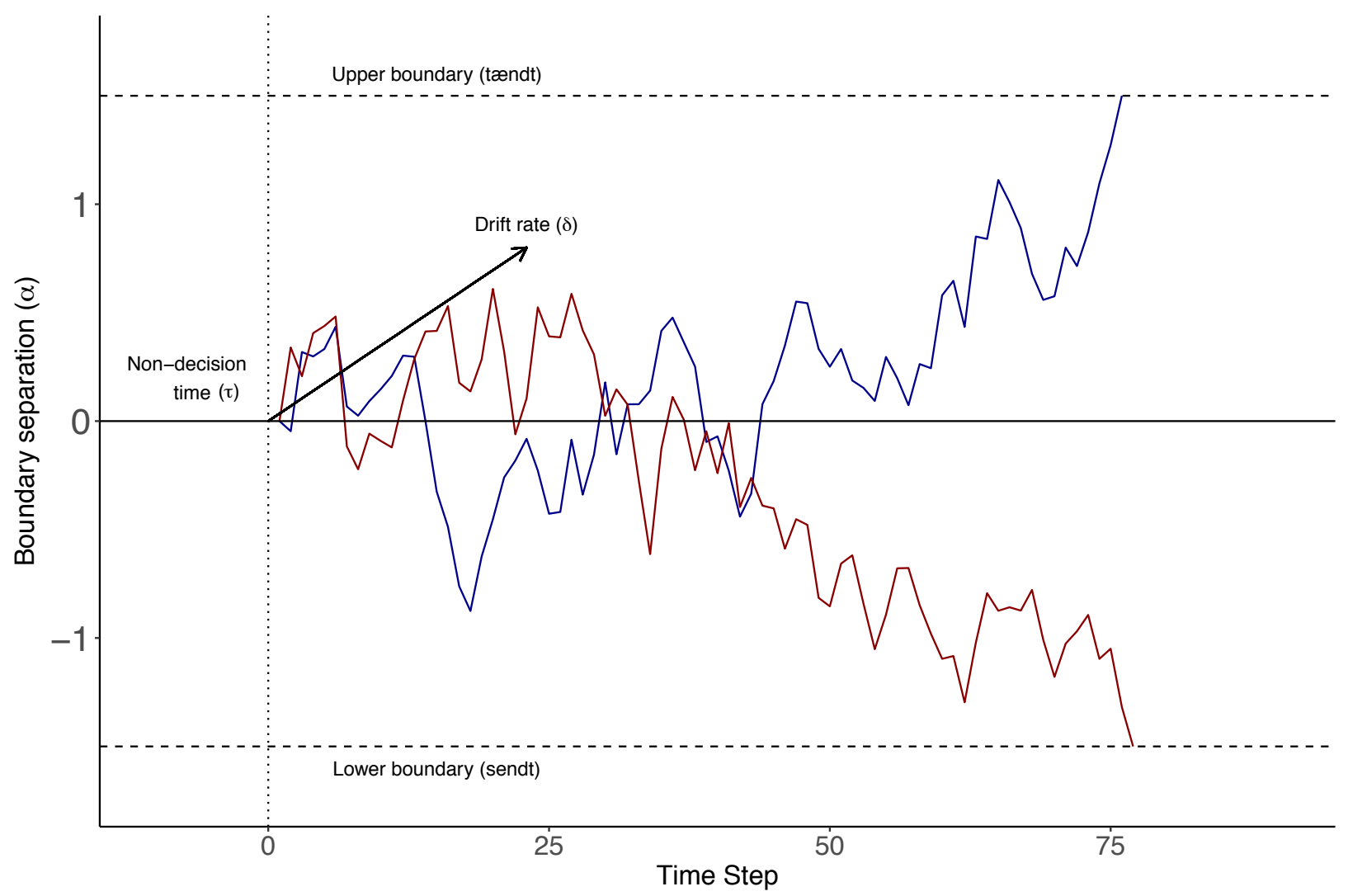

Figure 2: A schematic depiction of a DDM tailored to our study. Drift rate $(\delta)$ is the average rate of evidence accumulation. The boundary separation $(\alpha)$ is the distance between the upper boundary (response toendt) and lower boundary (response sendt). It depicts the amount of evidence necessary to make a decision. The starting point (b) is 0 and it shows there is no initial bias towards either the upper or the lower boundary. Non-decision-time ( $\boldsymbol{\tau})$ is the component of the RT that is 
Cross-linguistic differences in categorical perception

not involved in evidence accumulation (e.g., perception and encoding prior to evidence accumulation).

We conditioned drift rate and boundary separation on contextual bias (toendt/sendt), distance (NEAR/FAR) and the monotonic ordinal variable step as fixed effects, as shown in the formulae below:

Drift rate $\sim \alpha^{\text {Bias Distance }}+\beta^{\text {Bias Distance }}$ Step

Boundary separation $\sim \alpha^{\text {Bias Distance }}+\beta^{\text {Bias Distance }}$ Step

We assumed no biased preference for a specific response (bias $=0.5)$ and conditioned nondecision time on contextual bias. We set weakly informative priors for $\delta$ in each condition as a normal distribution with a mean of 0 and a $s d$ of 0.5 . Similarly, the priors for $\alpha$ were set as a normal distribution with a mean of 1.5 and a $s d$ of 0.5 . A full multilevel implementation of the DDM (with common hyperpriors partially pooling information across participants) presented worrisome divergences, so we ran the model on a participant-by-participant basis.

To assess effects of language, we then built a multilevel regression model with the posterior estimates of individual drift rate calculated at the mid-point of the step variable as outcome (thus relying on the most sensitive step for assessing contextual bias, see also Figure 3), and the abovementioned fixed effects - varying by participant - as well as language as predictors. For the followup model, we set priors for the drift rate estimate in each condition as a normal distribution with a mean of 0 and for its varying effects a mean of 0 and a $s d$ of 0.01 . In addition, we built a multilevel regression model with the posterior estimates of individual boundary separation calculated at the mid-point of the step variable as outcome. The latter is reported in the Supplementary Materials. 
The prior for the correlation across varying effects was modeled as a LKJ distribution with an eta of 8 , indicating low expectations for extreme correlation values close to 1 or -1 . We performed prior predictive checks to ensure these were weakly regularizing priors for the model, that is, priors that would exclude implausibly high values for the effects of the experimental manipulations while not affecting our results too much. To run the follow-up models using all 2000 samples was computationally prohibitive, so we iterated the models over 10 subsets of hundred posterior samples from each individual model and made sure their results were compatible between subsets. The DDMs were fitted using the STAN implementation of Hamiltonian Monte Carlo No-U-Turn samplers with an adapt delta of 0.99, a max tree depth of 20, 4000 iterations (of which 2000 were warmup) and 2 chains. The quality of the models was assessed relying on predictive priors, divergence assessment, $\hat{\mathrm{R}}(<1.1)$, ranked trace plots, effective samples $(>200)$ and predictive posteriors checks, and no warnings, nor other apparent issues were present in the models reported. Only the models using the first subset of samples are presented and analyzed in this paper. The rest displayed analogous results are reported in the supplementary materials.

In order to assess the evidence in favor or against our hypotheses, we rely on the Evidence Ratio (ER), that is, on the relative ratio of the number of posterior samples compatible with our hypothesis divided by the number of samples incompatible with it. The models were implemented using the brms (Bürkner, 2017) and RWiener (Wabersich \& Vandekerckhove, 2014) packages in RStudio v1.1.46, relying on STAN 3.19 (Gelman et al., 2015) and following the procedures described in Singmann (2017).

\section{Results}

The data show that the experimental manipulations produced general patterns in the directions expected from the literature in both Danish and Norwegian (Figure 3), i.e., a cross over 
in identification rate as a function of Step as well as a contextual biasing effect. As it can been seen in the figure, the propensity to respond toendt/tent increases as a function of step in the [s]$\left[\mathrm{t}^{\mathrm{s}}\right] /\left[\mathrm{t}^{\mathrm{h}}\right]$. The contextual bias effect on responding toendt/tent is the strongest at mid-point (Step $=$ 5) and disappears at the end points (Step $=1$ and Step $=10)$.

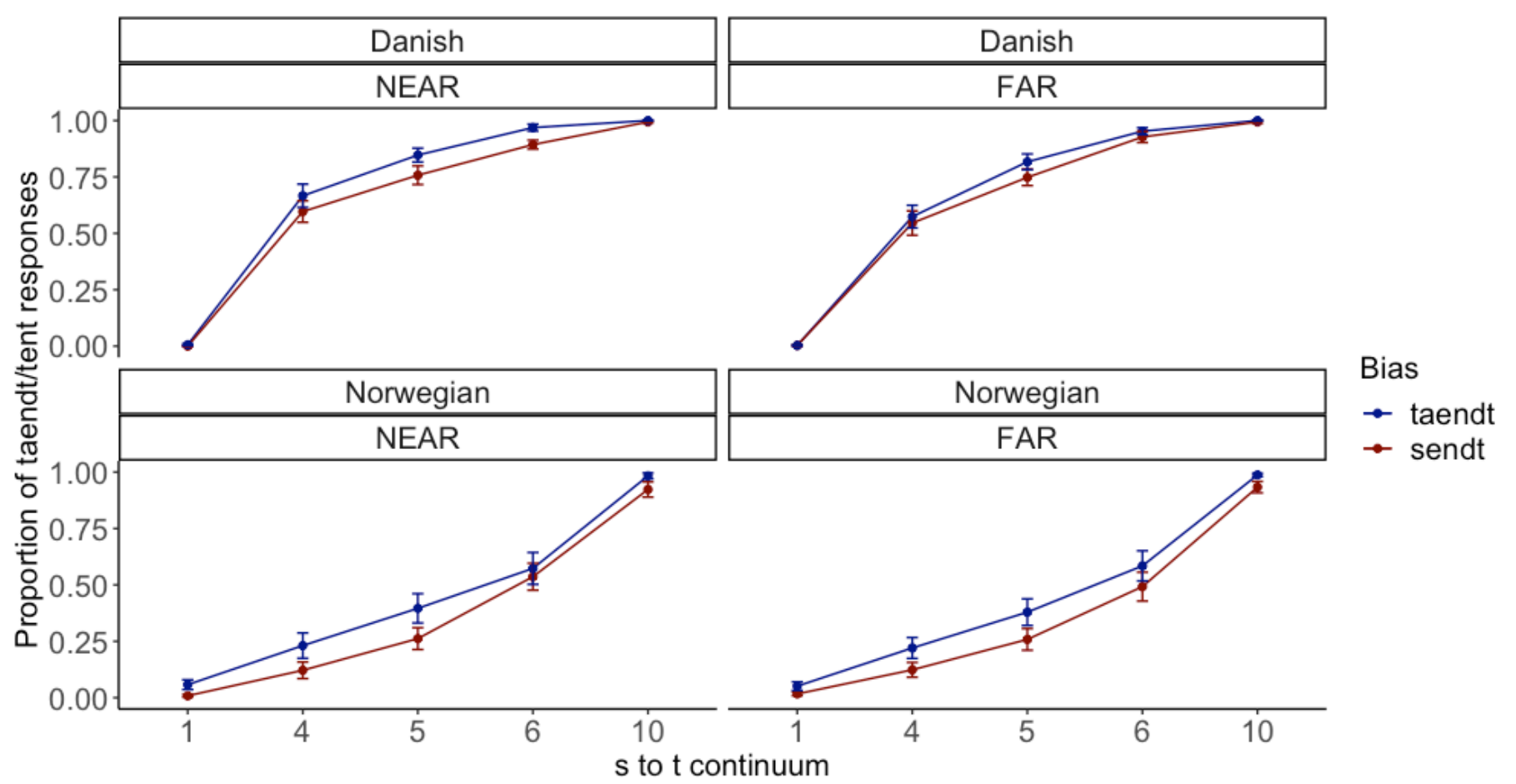

Figure 3: The mean propensity to respond toendt as a function of Step on the $[\mathrm{s}]-\left[\mathrm{t}^{\mathrm{s}}\right] /\left[\mathrm{t}^{\mathrm{h}}\right]$ continuum for Danish (top) and Norwegian (bottom) across distances NEAR (left) and FAR (right). The error bars correspond to the standard error of the mean.

Posterior estimates for the drift rate are presented in Table 3. Our main hypothesis (H1) was that the Bias $\mathrm{x}$ Distance interaction effect on drift rate would be smaller for Danish than for Norwegian (Bias x Distance x Language interaction). We found credible evidence supporting H1: the Bias x Distance interaction effect on drift rate $(\delta)$ was weaker in Danish than in Norwegian (Bias $\mathrm{x}$ Distance $\mathrm{x}$ Language three-way interaction: $\Delta \Delta \Delta \delta=0.07,95 \% \mathrm{CI}=[-0.01,0.15], \mathrm{ER}=$ 
Cross-linguistic differences in categorical perception

11.02; cf. Figure 4). In other words, while in Norwegian contextual bias was less pronounced with increased distance $(\Delta \Delta \delta=0.06,95 \% \mathrm{CI}=[0,0.12], \mathrm{ER}=20.51)$, it did change with distance in Danish $(\Delta \Delta \delta=-0.01,95 \% \mathrm{CI}=[-0.06,0.04], \mathrm{ER}=0.68)$. It should be noted that there was strong evidence supporting contextual bias across distance in both Danish (NEAR: $\Delta \delta=0.07,95 \% \mathrm{CI}=$ $[0.03,0.11], \mathrm{ER}=104.26$; FAR: $\Delta \delta=0.07,95 \% \mathrm{CI}=[0.04,0.11], \mathrm{ER}>1000)$ and Norwegian (NEAR: $\Delta \delta=0.11,95 \% \mathrm{CI}=[0.06,0.16], \mathrm{ER}>1000 ; \mathrm{FAR}: \Delta \delta=0.05,95 \% \mathrm{CI}=[0.01,0.1], \mathrm{ER}$ $>1000)$.

Table 3: Population level drift rate estimates at mid-point on the $[\mathrm{s}]-\left[\mathrm{t}^{\mathrm{s}}\right] /\left[\mathrm{t}^{\mathrm{h}}\right]$ continuum (Step =5) across languages (Danish and Norwegian), distances (NEAR and FAR) and biasing context (tcendt-bias and sendt-bias).

\begin{tabular}{|c|c|c|c|c|}
\hline & Danish & & Norwegian & \\
\hline & NEAR & & NEAR & \\
\hline & Estimate & $95 \% \mathrm{CI}$ & Estimate & $95 \% \mathrm{CI}$ \\
\hline toendt-bias & -0.20 & {$[-0.24 ;-0.15]$} & -0.6 & {$[-0.65,-0.55]$} \\
\hline \multirow[t]{3}{*}{ sendt-bias } & -0.27 & {$[-0.31 ;-0.22]$} & -0.71 & {$[-0.76,-0.66]$} \\
\hline & FAR & & FAR & \\
\hline & Estimate & $95 \% \mathrm{CI}$ & Estimate & $95 \% \mathrm{CI}$ \\
\hline
\end{tabular}


Cross-linguistic differences in categorical perception

\begin{tabular}{lllll}
\hline tcendt-bias & -0.14 & {$[-0.18 ;-0.10]$} & -0.48 & {$[-0.53,-0.43]$} \\
sendt-bias & -0.22 & {$[-0.25 ;-0.18]$} & -0.54 & {$[-0.58 ;-0.49]$} \\
\hline
\end{tabular}

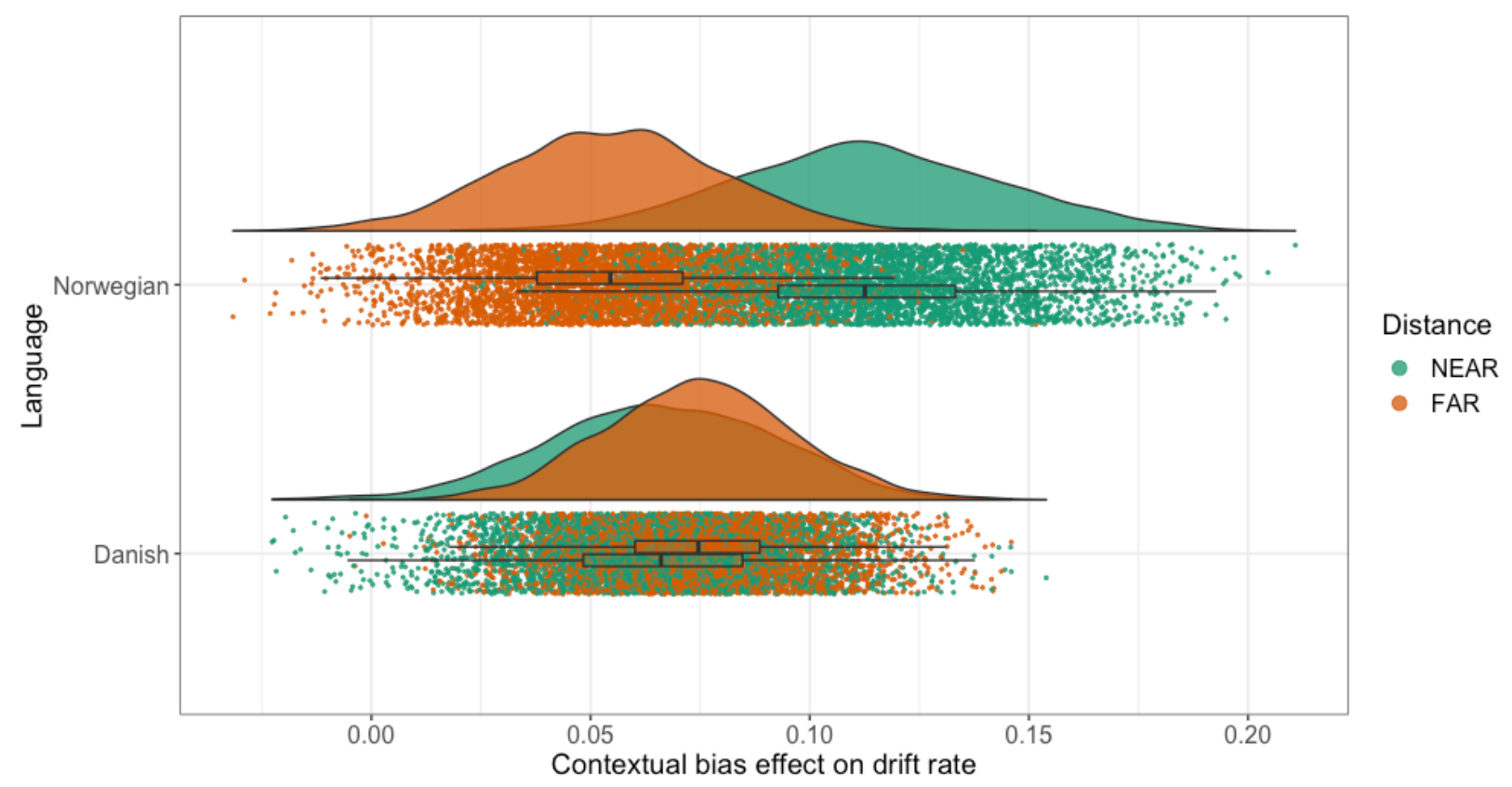

Figure 4: Posterior distributions of the bias effect on drift rate in the NEAR and FAR conditions per language with the individual data points extracted from posterior samples below. 
The evidence accumulation process inferred by the DDM is visualized in Figure 5. As it can be seen in the figure, Danish speakers generally accumulate information more slowly than Norwegian speakers (i.e., it takes longer for Danish speakers to make a decision compared to Norwegian speakers). Across languages and distances, it also takes longer to make a decision when the contextual bias is toendt.
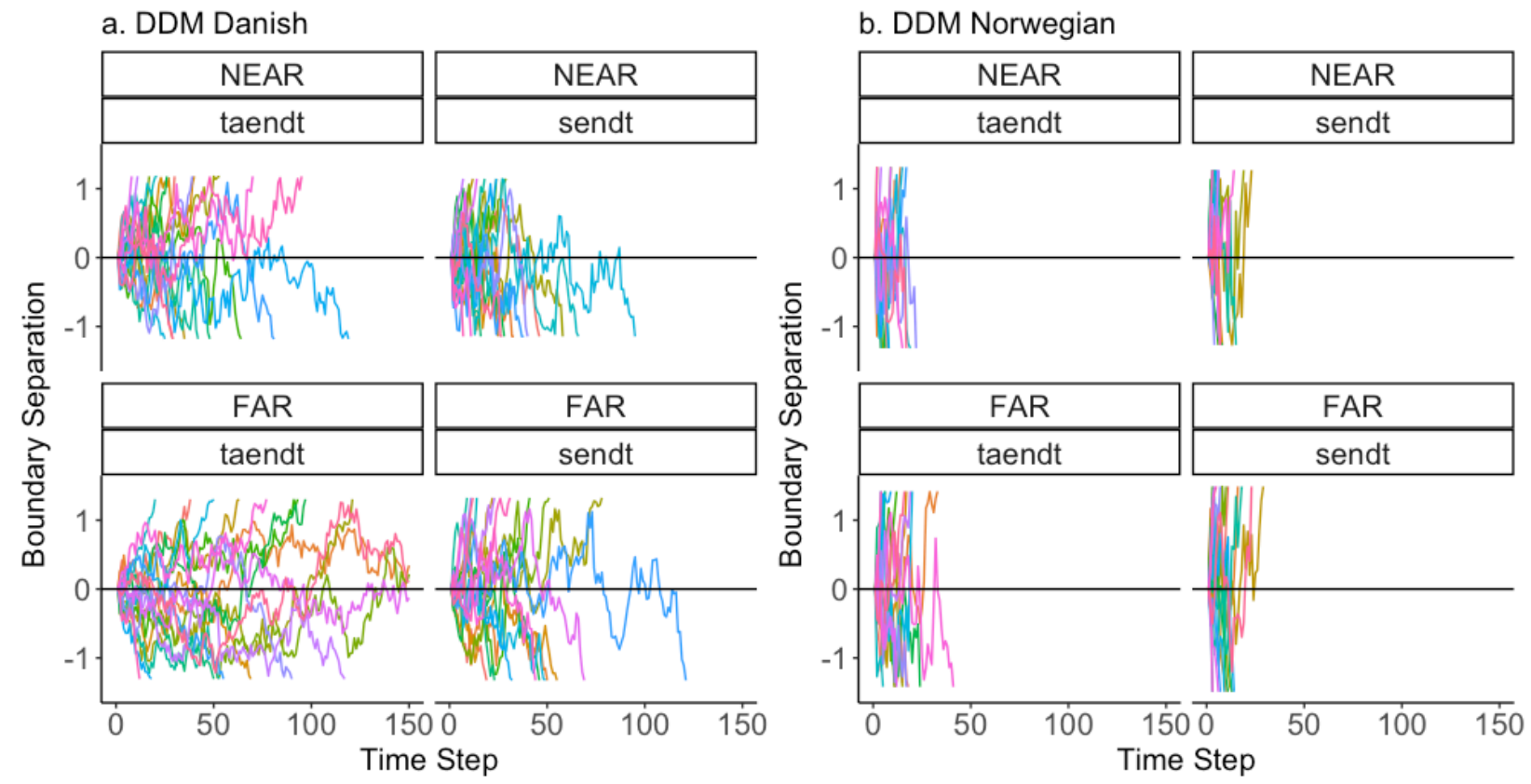

Figure 5: Twenty simulations of the drift diffusion model for Experiment $1 \mathrm{a}$. Danish and b. Norwegian in tcendt-bias (left panels) and sendt-bias (right panels) across distances NEAR (top) and FAR (bottom) at midpoint on the $[\mathrm{s}]-\left[\mathrm{t}^{\mathrm{s}}\right] /\left[\mathrm{t}^{\mathrm{h}}\right]$ continuum $($ Step $=5)$.

\section{Discussion}

The results show a cross-linguistic effect on categorical perception in Danish and Norwegian along the predicted directions. When presented with acoustic-phonetically ambiguous stimuli, 
Danish speakers relied on context equally when the target word was separated from the disambiguating word by one syllable (NEAR) and by 5-7 syllables (FAR). Norwegian speakers, on the contrary, showed a decreased bias effect in the FAR condition (like the English-speaking participants previously described in the literature: Connine et al., 1991; Szostak \& Pitt, 2013).

What could explain this cross-linguistic difference? We argue that the results indicate a difference in processing strategy between Danish and Norwegian speakers. As participants' ability to maintain the acoustic-phonetic information is limited, there is a pressure to make a decision before the acoustic information decay (Christiansen \& Chater, 2016). However, the phonological properties of Danish and Norwegian leads listeners to different strategies in regard to when to make a decision. We speculate that Norwegian speakers, due to the transparent phonology of Norwegian, put more weight on acoustic information and therefore make faster decisions while they still can access this information in phonological memory. In contrast, due to the opaque Danish phonology, Danish speakers are inclined to wait for supporting contextual information to inform their decision process. This creates similar performance in the NEAR condition, but a cross-linguistic difference in the FAR condition, where Norwegian speakers either do not wait for the disambiguating context to be available, or are not able to retain the acoustic-phonetic information for the duration of the disambiguating context sentence.

It is an open question whether the cross-linguistic difference is a consequence of an increased ability to maintain acoustic-phonetic information in Danish speakers, or simply a higher propensity of Danish speakers to wait in order to integrate more contextual information. To resolve this question, we conducted a second experiment adding the restriction that participants could only respond after the sentence offset, following the procedure of Bushong \& Jaeger (2017). If the cross-linguistic difference is explained by Norwegian speakers' inclination to respond before the 
Cross-linguistic differences in categorical perception

integration of the full context, we should observe a more Danish-like patterns in Norwegian speakers when forcing them to wait until the end of the sentence.

\section{Experiment 2}

Since Experiment 1 is compatible with several different interpretations, Experiment 2 investigates which factors are likely to cause the cross-linguistic difference between Danish and Norwegian speakers. In particular, the different responses to the FAR condition could either be due to Norwegian speakers not being able to retain the relevant sub-phonemic information in phonological memory, or because they rely on a different processing strategy that puts more weight on bottom-up acoustic information (thus disregarding the subsequent contextual information). By forcing the participants to wait until the end of the sentence to make a decision (as described for English by Bushong \& Jaeger, 2017), Experiment 2 aims to differentiate between these two hypotheses. If, in Norwegian speakers, the distance between the target and biasing words in the FAR condition is longer than their ability to retain sub-phonemic information, we expect the findings in Experiment 2 to be similar with those of Experiment 1. In other words, we expect a bigger effect of distance on contextual bias in Norwegian than in Danish. If, on the other hand, Norwegian speakers have similar memory capacities as Danish speakers, but rely on a different processing strategy, we would expect that forcing participants to wait would make Norwegian speakers' responses more similar to those of Danish speakers. In Experiment 2, we therefore tested the same hypothesis as in Experiment 1: Bias $\mathrm{x}$ Distance interaction is smaller in Danish than in Norwegian (Bias x Distance x Language interaction) (H2a) and we contrasted it to the additional hypothesis that there will be no cross-linguistic difference in Bias x Distance interaction (H2b). As in Experiment 1, we also tested additional hypotheses to check whether the results replicate. 
Cross-linguistic differences in categorical perception

\section{Method}

\section{Participants}

Forty-six Danish native speakers $($ female $=28$, age $=18-32$, median $=22, \mathrm{sd}=2.3$ ) and 35 Norwegian native speakers $($ female $=23$, age $=19-32$, median $=23, \mathrm{sd}=3.1$ ), different from the participants in Experiment 1, took part in this study. As in Experiment 1, the Danish speakers were recruited at the Cognition and Behavior Lab at Aarhus University in Denmark and the Norwegian participants were recruited at the Faculty of Humanities at the University of Bergen in Norway and fulfilled the same criteria as for Experiment 1. The participants received monetary compensation for participating in the study (the equivalent of about 26 USD), which again was part of a larger test battery.

\section{Materials \& Procedure}

In Experiment 2, we used the same materials as in Experiment 1. The procedure was also similar with the only difference being that the target words appeared on the screen only after the offset of the sentence stimuli, preventing participants from responding until then. As in Experiment 1, RTs were measured from the target word onset to the moment of the mouse click.

\section{Data analysis}

We followed the same procedure as defined for Experiment 1 and tested for the same effects as in Experiment 1. To the extent that the effects were not analogous across the experiments, we were interested in whether they were decreased due to the fast decay of the acoustic-phonetic information (as predicted by Connine et al., 1991) or increased due to contextual integration (as predicted by Bushong \& Jaeger, 2017). In the case of the former, we would expect the results in Experiment 2 to be similar to those in Experiment 1. In the case of the latter, in Experiment 2 we 
Cross-linguistic differences in categorical perception

would expect Norwegians to behave like Danes did in Experiment 1 (i.e., no distance effect on bias).

Following the same procedure as in Experiment 1, data from Experiment 2 was modelled using DDMs on a participant-by-participant basis. We then built a follow-up model with the posterior estimates of individual drift rate calculated at the mid-point of the step variable as outcome and the above-mentioned fixed effects - varying by participant - as well as language as predictors. For this model we set priors for the drift rate estimate in each condition as a normal distribution with a mean of 0 and a $s d$ of 0.5 and for its varying effects a mean of 0 and a $s d$ of 0.01. A more exploratory follow-up model assessing the differences in boundary separation is reported in the Supplementary Materials.

\section{Results}

The propensity to respond toendt/tent as a function of step in the $[\mathrm{s}]-\left[\mathrm{t}^{\mathrm{s}}\right] /\left[\mathrm{t}^{\mathrm{h}}\right]$ continuum and contextual bias is reported in Figure 6. As evident from the figure, similar to Experiment 1, the propensity to respond tcendt/tent increases as a function of step in the $[\mathrm{s}]-\left[\mathrm{t}^{\mathrm{s}}\right] /\left[\mathrm{t}^{\mathrm{h}}\right]$. The contextual bias effect at the midpoint of the continuum (Step $=5$ ), however, is less prominent compared to Experiment 1. 
Cross-linguistic differences in categorical perception
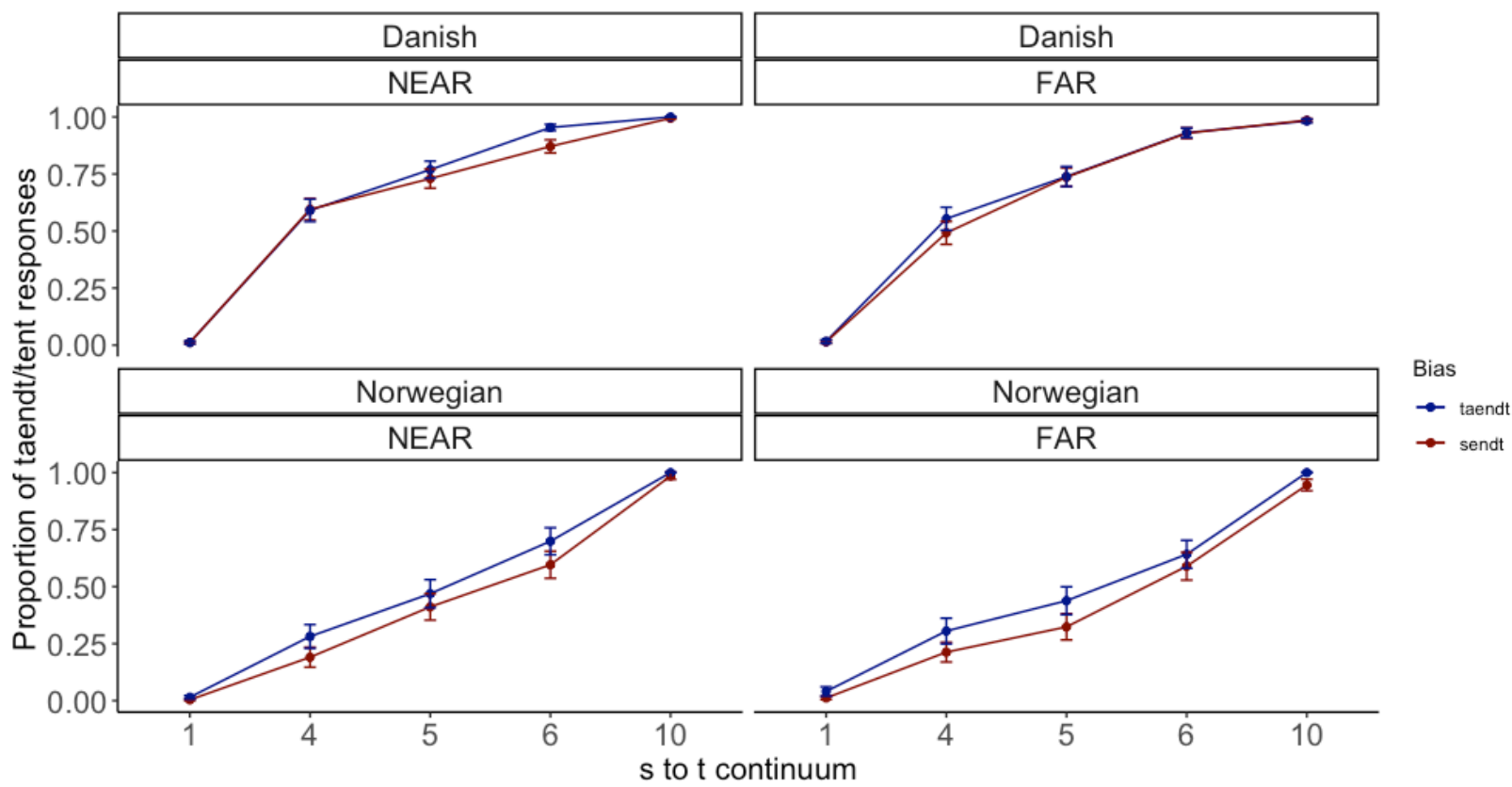

Figure 6: The mean propensity to respond tcendt as a function of Step on the $[\mathrm{s}]-\left[\mathrm{t}^{\mathrm{s}}\right] /\left[\mathrm{t}^{\mathrm{h}}\right]$ continuum for Danish (top) and Norwegian (bottom) across distances NEAR (left) and FAR (right). The error bars correspond to the standard error of the mean.

Full details for the analysis of drift rate - which is based on both responses and RTs - are presented in Table 4. There was moderate evidence for cross-linguistic differences in Bias $\mathrm{x}$ Distance interaction in Experiment $2(\mathrm{H} 2 \mathrm{a}: \Delta \Delta \Delta \delta=0.05,95 \% \mathrm{CI}=[-0.01,0.13], \mathrm{ER}=10.46)$ (Figure 7). In support of $\mathrm{H} 2 \mathrm{~b}$, there was no evidence supporting a stronger contextual bias effect in NEAR than in FAR either in Danish $(\Delta \Delta \delta=-0.05,95 \% \mathrm{CI}=[-0.1,0], \mathrm{ER}=0.04)$ or Norwegian $(\Delta \Delta \delta=0.01,95 \% \mathrm{CI}=[-0.05,0.07], \mathrm{ER}=1.7)$. In Danish this was due to lack of a bias effect in $\operatorname{NEAR}(\Delta \delta=0.01,95 \% \mathrm{CI}=[-0.03,0.05], \mathrm{ER}=1.75)$, whereas there was strong evidence supporting bias effect in FAR condition $(\Delta \delta=0.06,95 \% \mathrm{CI}=[0.02,0.09], \mathrm{ER}=265.67)$. As for Norwegian, there was strong evidence for contextual bias both in the NEAR $(\Delta \delta=0.1,95 \% \mathrm{CI}=$ $[0.05,0.14], \mathrm{ER}>1000)$ and the FAR condition $(\Delta \delta=0.09,95 \% \mathrm{CI}=[0.05,0.13], \mathrm{ER}>1000)$. Thus, the language $\mathrm{x}$ Bias $\mathrm{x}$ Distance interaction was a result of the bias effect being equally strong 
in NEAR and FAR in Norwegian (H2b) while even shifting in the opposite direction in Danish (stronger in FAR than NEAR). There was also no evidence for the bias being stronger in Danish than in Norwegian either in the NEAR $(\Delta \Delta \delta=-0.09,95 \% \mathrm{CI}=[-0.15,-0.03], \mathrm{ER}=0.01)$ or the FAR condition $(\Delta \Delta \delta=-0.03,95 \% \mathrm{CI}=[-0.08,0.03], \mathrm{ER}=0.24)($ Figure 7$)$. Figure 8 represents simulation of the DDM for Experiment 2. As it can be seen in the figure, Norwegian speakers still make their decision earlier than Danish speakers (despite no obvious differences in RT distributions between the languages, see Supplementary Materials for the distributions). The bias effect in the NEAR and FAR conditions in Norwegian may not seem as prominent due to scaling (The $\mathrm{x}$-axis has been scaled in a way to show the simulations in Danish and the same scale has been used for Norwegian for consistency). See Supplementary Materials for full details on the model. 
Cross-linguistic differences in categorical perception

Table 4: Population level drift rate estimates at mid-point on the $[\mathrm{s}]-\left[\mathrm{t}^{\mathrm{s}}\right] /\left[\mathrm{t}^{\mathrm{h}}\right]$ continuum (Step =5) across languages (Danish and Norwegian), distances (NEAR and FAR) and biasing context (toendt-bias and sendt-bias).

\begin{tabular}{|c|c|c|c|c|}
\hline & \multicolumn{2}{|l|}{ Danish } & \multicolumn{2}{|c|}{ Norwegian } \\
\hline & NEAR & & NEAR & \\
\hline & Estimate & $95 \% \mathrm{CI}$ & Estimate & $95 \% \mathrm{CI}$ \\
\hline toendt-bias & -0.24 & {$[-0.29 ;-0.20]$} & -0.61 & {$[-0.66,-0.56]$} \\
\hline \multirow[t]{3}{*}{ sendt-bias } & -0.25 & {$[-0.29 ;-0.21]$} & -0.71 & {$[-0.76,-0.66]$} \\
\hline & FAR & & FAR & \\
\hline & Estimate & $95 \% \mathrm{CI}$ & Estimate & $95 \% \mathrm{CI}$ \\
\hline toendt-bias & -0.12 & {$[-0.16 ;-0.08]$} & -0.43 & {$[-0.48,-0.38]$} \\
\hline sendt-bias & -0.18 & {$[-0.22 ;-0.14]$} & -0.52 & {$[-0.56 ;-0.47]$} \\
\hline
\end{tabular}


Cross-linguistic differences in categorical perception

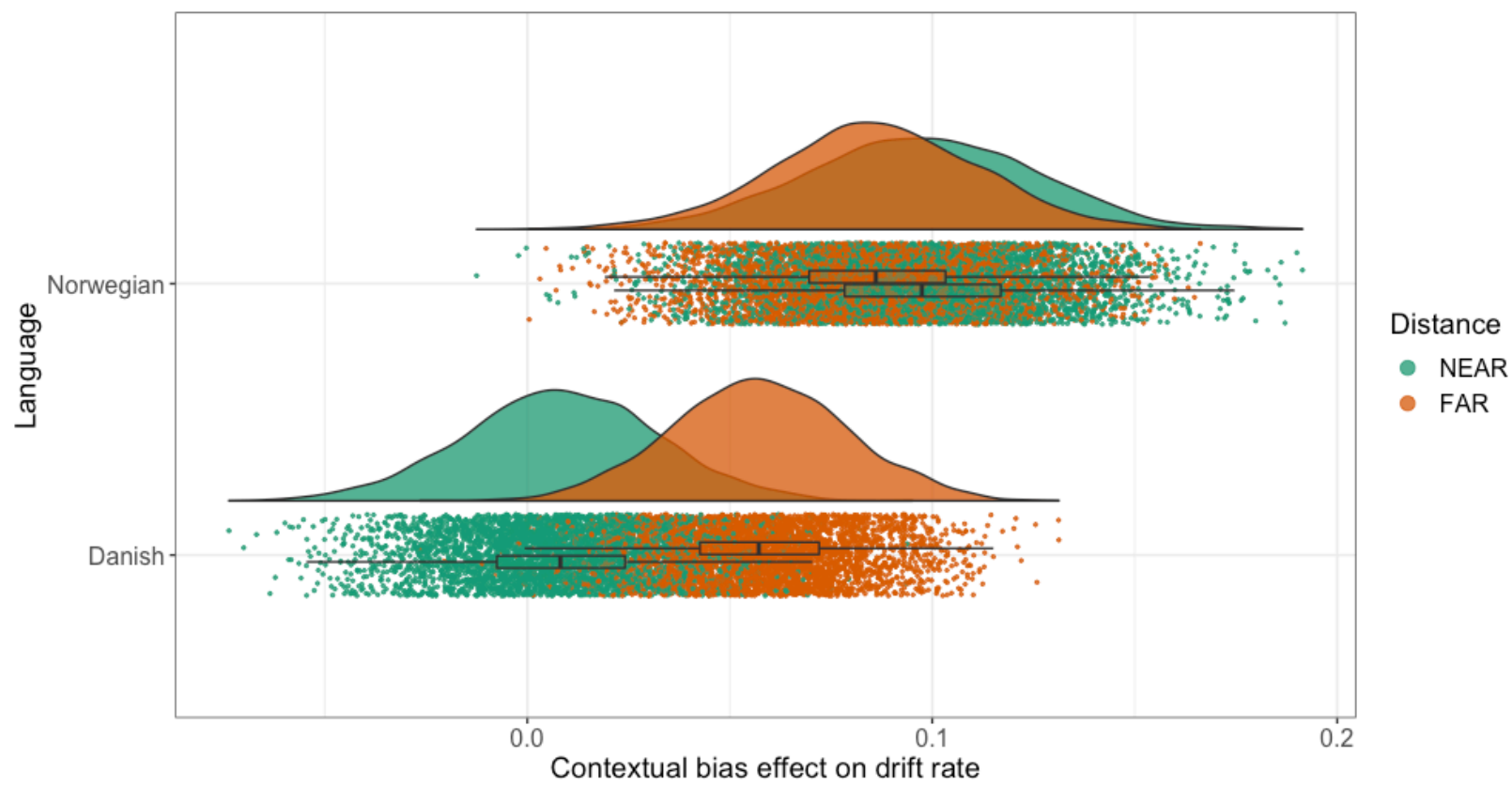

Figure 7: Posterior distributions of the contextual bias effect on drift rate in the NEAR and FAR distances per language with the actual posterior samples below. 

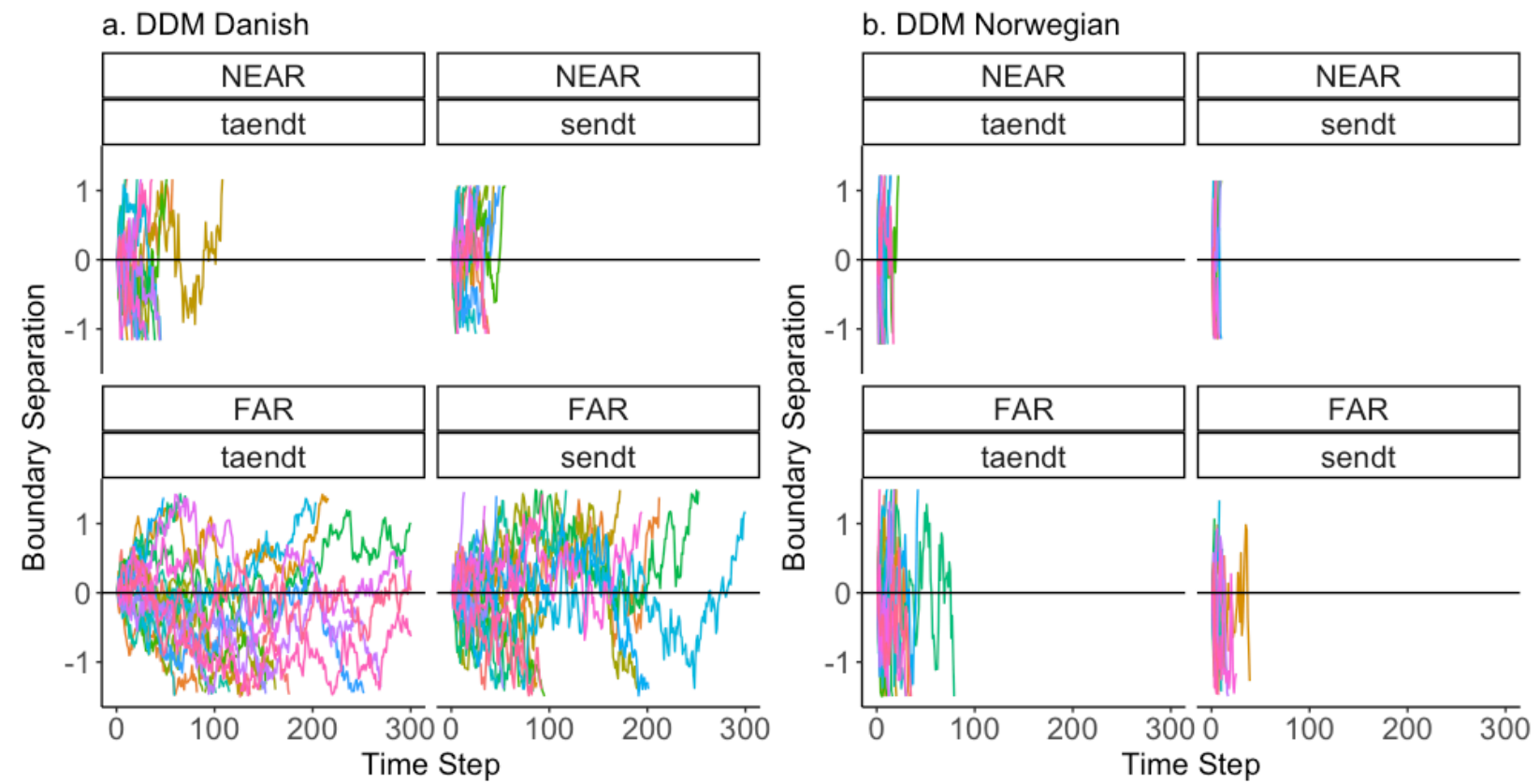

Figure 8: Twenty simulations of the drift diffusion model for Experiment $2 \mathrm{a}$. Danish and b. Norwegian in tændt-bias (left panels) and sendt-bias (right panels) across distances NEAR (top) and FAR (bottom) at midpoint on the $[\mathrm{s}]-\left[\mathrm{t}^{\mathrm{s}}\right] /\left[\mathrm{t}^{\mathrm{h}}\right]$ continuum $($ Step $=5)$.

\section{Discussion}

The results of Experiment 2 show that when forced to wait until the stimulus offset, distance ceases to affect contextual bias in Norwegian speakers. In other words, when Norwegian speakers have to wait for the supporting FAR context before they can respond, their response is biased by this information. That is, they start behaving like the Danish speakers in Experiment 1 supporting Hypothesis $2 \mathrm{~b}$. This suggests that the cross-linguistic difference observed in Experiment 1 is not due to differences in the capacity to sustain acoustic-phonetic information between Norwegians and Danes. Rather, it points to differences in the processing strategy used by speakers of Norwegian and Danish. Since Norwegians are more inclined to weigh the bottom-up acoustic 
Cross-linguistic differences in categorical perception

information, which is more transparent in Norwegian, they have a propensity to respond soon after the presentation of this information, which caused the smaller bias effect in the FAR condition of Experiment 1.

Unexpectedly, we still observe a cross-linguistic difference in Experiment 2: the absolute effect of distance on contextual bias was larger in Danish than in Norwegian. For Danish speakers, the effects of contextual biases disappear in the NEAR condition, while they are still evident in the FAR condition. This is unexpected, and cannot be explained by reference to phonological memory limitations, given that the bias effect was present in the FAR condition. Rather, it suggests that Danish speakers also switched their strategy in response to the setup of Experiment 2 where the target responses appeared on the screen only after sentence offset. We speculate that due to more fine-grained phonological representations, developed to compensate for the opaque speech signal, Danish speakers might be able to respond to the NEAR condition relying on the subphonemic information alone to categorize the target words. Such a strategy corresponds to the categorize-and-discard model suggested by Bushong and Jaeger (2019a) and the Now-or-Never bottleneck suggested by Christiansen and Chater (2016). While this explanation may seem incompatible with the idea of a general attraction to context in Danes, it is compatible with the observation - also made for Norwegians - that linguistic processing strategies are flexibly adapted to the task at hand (Gibson et al., 2017; Trecca et al., 2019; Yurovsky et al., 2017). 


\section{General Discussion}

\section{Cross-linguistic differences}

We investigated the role of cross-linguistic differences in the effect of contextual bias on phoneme categorization, adapting paradigms previously used for American English to two typologically related languages: Danish and Norwegian (Connine et al., 1991; Szostak \& Pitt, 2013; Bushong \& Jaeger, 2017). Danish is characterized by a more opaque phonology than Norwegian, which led us to expect stronger effects of top-down contextual biases in Danish speakers. In Experiment 1, we indeed found that Danish speakers were affected by context independently of the distance between the target and the biasing word, whereas Norwegian speakers were less affected by context when this was presented at an increased distance from the target (like the American English speakers described in Connine et al., 1991; Szostak \& Pitt, 2013). To investigate whether this was due to differences in phonological memory, or to a cognitive strategy asserting more weight on contextual information, we designed a second experiment. In Experiment 2, we manipulated the instructions and the experimental script such that the participants could respond only after the offset of the stimulus sentence. When forced to wait, Norwegian speakers behaved more like the Danish speakers in Experiment 1, that is, Norwegians showed the same contextual bias in NEAR and FAR conditions.

These results provide evidence that despite the languages being closely related, there are differences in the processing strategies applied by Danish and Norwegian speakers. We suggest that these differences are motivated by typological factors, in particular the peculiar opaque sound structure of Danish. Our observations add to the existing literature suggesting that Danish is difficult to acquire both as a first and second language, and indeed the most difficult to understand among Scandinavian languages (Bleses et al., 2008, 2011; Gooskens et al., 2010; Grønnum, 2003; 
Jespersen \& Hejná, 2019; Trecca et al., submitted). While we have no evidence to suggest that the prevalent opaque sound structure of Danish impedes everyday communication between Danes, the current study provides evidence that adult Danish speakers implement cognitive strategies to compensate for the acoustic-phonetic ambiguity. More generally, the current findings support the idea that typological differences can have psycholinguistic implications at the level of processing (e.g., Evans \& Levinson, 2009), in particular with respect to the extent to which speakers weigh various forms of bottom-up and top-down information (Trecca et al., 2019).

Importantly, the differences are not structural in the sense of, for instance, phonological memory, but can be mitigated through changing the task demands. As shown in Experiment 2, when forced to wait until sentence offset, Norwegian speakers did in fact integrate the extra contextual information resulting in response behaviors similar to those of Danish speakers in Experiment 1.

\section{The Drift diffusion model approach}

In the current study, we integrated responses and response times in a single model, which provides more nuanced information about the processes involved in phoneme categorization. Thus, it was possible to measure not only what kind of decision the participants made but also how fast (or slow) they accumulated information to reach that decision.

Although we had chosen the mid-point as a maximally ambiguous point on the $[\mathrm{s}]-\left[\mathrm{t}^{\mathrm{s}}\right] /\left[\mathrm{t}^{\mathrm{h}}\right]$ continuum, the general negative value of drift rate - independent of the biasing context - suggests a stronger preference for the sendt response (lower boundary) in both Danish and Norwegian participants. This may be due to fricatives having a longer memory trace than plosives (Szostak \& Pitt, 2013), which resulted in maintenance of the frication noise and not the silent interval. The toendt biasing context slowed down evidence accumulation for the lower boundary (incongruence 
between the acoustic-phonetic input and the context). Thus, there was a bias effect observed across languages and distances. It is also possible that individual participants had different categorical boundaries (see Supplementary Materials). As a result, the choice of the mid-point may not have captured all the participant's maximally ambiguous point, which could be another potential explanation for the somewhat unexpected results for Danish in Experiment 2 (as participants in Experiment 2 were different from the ones in Experiment 1). A potential solution to this problem in a future study could be to staircase the stimuli individually to ensure that the participants are always exposed to their own maximally ambiguous points.

When we compare the DDM findings to the plots of the raw response-only data (Figure 3 and Figure 6), it becomes clear that the DDM, due to the additional integration of RTs, provides additional and more nuanced information about the categorization process. In particular, in the case of Experiment 2, the plot (Figure 6) could seem incompatible with the findings of the DDM (Figure 7) with the bias effect looking completely absent in Danish FAR condition and minuscule in the NEAR condition (though slightly more prominent in Step =6). Importantly, this apparent discrepancy arises from the type of extra information the drift rate provides: there may not be a bias effect in the categorical responses Danish speakers make in the FAR condition, rather the bias effect is expressed in the time it takes them to accumulate evidence to make their choice.

\section{Limitations and future studies}

While Danish and Norwegian are closely related languages and our experimental stimuli were well-matched, there are important factors pertaining to dialectical variation and language policies in Denmark and Norway. While in Denmark, all the dialects are converging to the standard Copenhagen dialect, Norway have active dialects and does not have a standard language; Basbøll, 2005; Kristoffersen, 2000). This could have potentially resulted in larger individual differences in 
Norwegian speakers, compared to Danish speakers (as seen in the larger standard deviations of the different effects in Norwegian, compared to Danish, reported in the Supplementary Materials).

A second potential limitation to the current study is that due to model convergence issues, it was not possible to fit the data to a model in a single step. Instead, models were fitted on a participant-by-participant basis. A single model integrating the entire dataset would have been preferred, allowing for partial pooling of information between participants and could potentially yield more robust statistical inferences.

\section{Conclusions}

The current study provides evidence of cross-linguistic processing differences between the closely related languages Danish and Norwegian. Due to the opaque sound structure of Danish relative to Norwegian, we suggest that Danish speakers weigh top-down contextual information more in their linguistic categorization processes. In Experiment 1, Danes thus tended to use context to a similar extent when it was separated from the ambiguous acoustic target information by one or many syllables, whereas Norwegian speakers reduce their reliance on context when the distance is increased. These strategies changed when the task demands changed: when forced to listen to the context, Norwegian speakers started behaving more like Danish speakers suggesting that the observed differences are due to the processing strategies utilized by Danes and Norwegians respectively, in particular the relative weighting of bottom-up and top-down information when making categorical decisions. Our findings suggest that speakers of different languages might rely on different processing differences contingent on typological differences, even in closely related languages, such as Danish and Norwegian, and these differences can be mitigated by task demands and can be meaningfully modeled to better understand cognition. 


\section{Acknowledgements}

This research was partially supported by Danish Council for Independent Research (FKK) Grant DFF-7013-00074 awarded to Morten H. Christiansen. The authors thank Dorthe Bleses for her input in designing the experiments, Gjert Kristoffersen for providing insightful comments on Norwegian phononology, Rikke Kjems Christensen, Christina Dideriksen and Fabio Trecca for assisting the data collection in Denmark and in Norway, Morten Hammershøy Kølln for helping with the graphics of Figure 1, Cognition and Behavior Lab for providing the lab facilities and researchers at the Interacting Minds Centre and at the Phon-Phon for Phun group at Aarhus University for their feedback on the early results and all the study participants both in Denmark and Norway.

\section{References}

Basbøll, H. (2005). The phonology of Danish. Oxford University Press.

Beretti, Havron, N., \& Christophe, A. (2020). 4-5-year-old children adapt to the reliability of conflicting sources of information to learn novel words [Preprint]. PsyArXiv. https://doi.org/10.31234/osf.io/k5tbm

Bleses, D., Basbøll, H., \& Vach, W. (2011). Is Danish difficult to acquire? Evidence from Nordic past-tense studies. Language and Cognitive Processes, 26(8), 1193-1231. https://doi.org/10.1080/01690965.2010.515107 
Cross-linguistic differences in categorical perception

Bleses, D., Vach, W., Slott, M., Wehberg, S., Thomsen, P., Madsen, T. O., \& Basbøll, H. (2008). The Danish Communicative Developmental Inventories: Validity and main developmental trends. Journal of Child Language, 35(3), 651-669. https://doi.org/10.1017/S0305000907008574

Borsky, S., Tuller, B., \& Shapiro, L. P. (1998). "How to milk a coat:” The effects of semantic and acoustic information on phoneme categorization. The Journal of the Acoustical Society of America, 103(5), 2670-2676. https://doi.org/10.1121/1.422787

Brown-Schmidt, S., \& Toscano, J. C. (2017). Gradient acoustic information induces long-lasting referential uncertainty in short discourses. Language, Cognition and Neuroscience, 32(10), 1211-1228. https://doi.org/10.1080/23273798.2017.1325508

Bürkner, P.-C. (2017). Advanced Bayesian Multilevel Modeling with the R Package brms. ArXiv:1705.11123 [Stat]. http://arxiv.org/abs/1705.11123

Bushong, W., \& Jaeger, T. F. (2017). Maintenance of perceptual information in speech perception. Paper presented at the Thirty-Ninth Annual Conference of the Cognitive Science Society.

Bushong, W., \& Jaeger, T. F. (2019). Dynamic re-weighting of acoustic and contextual cues in spoken word recognition. The Journal of the Acoustical Society of America, 146(2), EL135-EL140. https://doi.org/10.1121/1.5119271

Casillas, M., Brown, P., \& Levinson, S. C. (2019). Early Language Experience in a Tseltal Mayan Village. Child Development, cdev.13349. https://doi.org/10.1111/cdev.13349

Chodroff, E., \& Wilson, C. (2020). Acoustic-phonetic and auditory mechanisms of adaptation in the perception of sibilant fricatives. Attention, Perception, \& Psychophysics, 82(4), 20272048. https://doi.org/10.3758/s13414-019-01894-2 
Cross-linguistic differences in categorical perception

Christiansen, M. H., \& Chater, N. (2016). The Now-or-Never bottleneck: A fundamental constraint on language. Behavioral and Brain Sciences, 39, e62. https://doi.org/10.1017/S0140525X1500031X

Connine, C. M., Blasko, D. G., \& Hall, M. (1991). Effects of subsequent sentence context in auditory word recognition: Temporal and linguistic constrainst. Journal of Memory and Language, 30(2), 234-250. https://doi.org/10.1016/0749-596X(91)90005-5

Cutler, A., Dahan, D., \& van Donselaar, W. (1997). Prosody in the Comprehension of Spoken Language: A Literature Review. Language and Speech, 40(2), 141-201. https://doi.org/10.1177/002383099704000203

Evans, N., \& Levinson, S. C. (2009). The myth of language universals: Language diversity and its importance for cognitive science. Behavioral and Brain Sciences, 32(5), 429-448. https://doi.org/10.1017/S0140525X0999094X

Gaskell, M. G., \& Marslen-Wilson, W. D. (2001). Lexical Ambiguity Resolution and Spoken Word Recognition: Bridging the Gap. Journal of Memory and Language, 44(3), 325-349. https://doi.org/10.1006/jmla.2000.2741

Gelman, A., Lee, D., \& Guo, J. (2015). Stan: A Probabilistic Programming Language for Bayesian Inference and Optimization. Journal of Educational and Behavioral Statistics, 40(5), 530543. https://doi.org/10.3102/1076998615606113

Gibson, E., Tan, C., Futrell, R., Mahowald, K., Konieczny, L., Hemforth, B., \& Fedorenko, E. (2017). Don't Underestimate the Benefits of Being Misunderstood. Psychological Science, 28(6), 703-712. https://doi.org/10.1177/0956797617690277

Goblirsch, K. G. (2002). On the development of Germanic consonants. The Danish shift and the Danish lenition. Beiträge Zur Geschichte Der Deutschen Sprache Und Literatur (PBB), 124(2), 199-232. https://doi.org/10.1515/BGSL.2002.199 
Cross-linguistic differences in categorical perception

Gooskens, C., van Heuven, V. J., van Bezooijen, R., \& Pacilly, J. J. A. (2010). Is spoken Danish less intelligible than Swedish? Speech Communication, 52(11-12), 1022-1037. https://doi.org/10.1016/j.specom.2010.06.005

Grønnum, N. (1998). Danish. Journal of the International Phonetic Association, 28(1-2), 99-105. https://doi.org/10.1017/S0025100300006290

Henrich, J., Heine, S. J., \& Norenzayan, A. (2010). Beyond WEIRD: Towards a broad-based behavioral science. Behavioral and Brain Sciences, 33(2-3), 111-135. https://doi.org/10.1017/S0140525X10000725

Ishkhanyan, B., Højen, A., Fusaroli, R., Johansson, C., Tylén, K., \& Christiansen, M. H. (2019). Wait for it! Stronger influence of context on categorical perception in Danish than Norwegian. In A. Goel, C. Seifert \& C. Freksa (Eds.), Proceedings of the 41st Annual Conference of the Cognitive Science Society, 1949-1955. Presented at the 41st Annual Conference of the Cognitive Science Society, Montreal, Quebec. Austin, TX: Cognitive Science Society. https://doi.org/10.31234/osf.io/guzv5

Kamide, Y., Altmann, G. T. M., \& Haywood, S. L. (2003). The time-course of prediction in incremental sentence processing: Evidence from anticipatory eye movements. Journal of Memory and Language, 49(1), 133-156. https://doi.org/10.1016/S0749-596X(03)00023-8

Kintsch, W. (2005). An Overview of Top-Down and Bottom-Up Effects in Comprehension: The CI Perspective. Discourse Processes, 39(2-3), 125-128. https://doi.org/10.1080/0163853X.2005.9651676

Kristoffersen, G. (2000). The phonology of Norwegian. Oxford University Press. 
Cross-linguistic differences in categorical perception

Lerche, V., \& Voss, A. (2016). Model Complexity in Diffusion Modeling: Benefits of Making the Model More Parsimonious. Frontiers in Psychology, 7. https://doi.org/10.3389/fpsyg.2016.01324

Liberman, A. M., Harris, K. S., Hoffman, H. S., \& Griffith, B. C. (1957). The discrimination of speech sounds within and across phoneme boundaries. Journal of Experimental Psychology, 54(5), 358-368. https://doi.org/10.1037/h0044417

MacDonald, M. C., Pearlmutter, N. J., \& Seidenberg, M. S. (1994). The lexical nature of syntactic ambiguity resolution. Psychological Review, 101(4), 676-703. https://doi.org/10.1037/0033-295X.101.4.676

Marslen-Wilson, W. D., \& Welsh, A. (1978). Processing interactions and lexical access during word recognition in continuous speech. Cognitive Psychology, 10(1), 29-63. https://doi.org/10.1016/0010-0285(78)90018-X

McCauley, S. M., \& Christiansen, M. H. (2019). Language learning as language use: A crosslinguistic model of child language development. Psychological Review, 126(1), 1-51. https://doi.org/10.1037/rev0000126

McMurray, B., Tanenhaus, M. K., \& Aslin, R. N. (2009). Within-category VOT affects recovery from "lexical" garden-paths: Evidence against phoneme-level inhibition. Journal of Memory and Language, 60(1), 65-91. https://doi.org/10.1016/j.jml.2008.07.002

Nieuwland, M. S., \& Van Berkum, J. J. A. (2006). When Peanuts Fall in Love: N400 Evidence for the Power of Discourse. Journal of Cognitive Neuroscience, 18(7), 1098-1111. https://doi.org/10.1162/jocn.2006.18.7.1098

Otten, M., \& Van Berkum, J. J. A. (2008). Discourse-Based Word Anticipation During Language Processing: Prediction or Priming? Discourse Processes, 45(6), 464-496. https://doi.org/10.1080/01638530802356463 
Cross-linguistic differences in categorical perception

Peirce, J., \& MacAskill, M. (2018). Building experiments in PsychoPy. Sage.

Petitot, J. (1988). MORPHODYNAMICS AND THE CATEGORICAL PERCEPTION OF PHONOLOGICAL UNITS. Theoretical Linguistics, 15(1-2). https://doi.org/10.1515/thli.1988.15.1-2.25

Pinker, S., \& Bloom, P. (1990). Natural language and natural selection. Behavioral and Brain Sciences, 13(4), 707-727. https://doi.org/10.1017/S0140525X00081061

Ratcliff, R. (1978). A theory of memory retrieval. Psychological Review, 85(2), 59-108. https://doi.org/10.1037/0033-295X.85.2.59

Ratcliff, R., \& McKoon, G. (2008). The Diffusion Decision Model: Theory and Data for TwoChoice Decision Tasks. Neural Computation, 20(4), 873-922. https://doi.org/10.1162/neco.2008.12-06-420

Ratcliff, R., Smith, P. L., Brown, S. D., \& McKoon, G. (2016). Diffusion Decision Model: Current Issues and History. Trends in Cognitive Sciences, 20(4), 260-281. https://doi.org/10.1016/j.tics.2016.01.007

Roark, B. (2001). Probabilistic Top-Down Parsing and Language Modeling. Computational Linguistics, 27(2), 249-276. https://doi.org/10.1162/089120101750300526

Schiller, N. O., \& Meyer, A. (Eds.). (2003). Phonetics and phonology in language comprehension and production: Differences and similarities. Mouton de Gruyter.

Stafford, T., Pirrone, A., Croucher, M., \& Krystalli, A. (2020). Quantifying the benefits of using decision models with response time and accuracy data. Behavior Research Methods. https://doi.org/10.3758/s13428-020-01372-w

Szostak, C. M., \& Pitt, M. A. (2013). The prolonged influence of subsequent context on spoken word recognition. Attention, Perception, \& Psychophysics, 75(7), 1533-1546. https://doi.org/10.3758/s13414-013-0492-3 
Cross-linguistic differences in categorical perception

Trecca, F., Bleses, D., Højen, A., Madsen, T. O., \& Christiansen, M. H. (2020). When Too Many Vowels Impede Language Processing: An Eye-Tracking Study of Danish-Learning Children. Language and $\quad$ Speech, 002383091989339. https://doi.org/10.1177/0023830919893390

Trecca, F., Bleses, D., Madsen, T. O., \& Christiansen, M. H. (2018). Does sound structure affect word learning? An eye-tracking study of Danish learning toddlers. Journal of Experimental Child Psychology, 167, 180-203. https://doi.org/10.1016/j.jecp.2017.10.011

Trecca, F., Tylén, K., Fusaroli, R., Johansson, C., \& Christiansen, M. H. (2019). Top- down information is more important in noisy situations: Exploring the role of pragmatic, semantic, and syntactic information in language processing. In A. Goel, C. Seifert \& C. Freksa (Eds.), Proceedings of the 41st Annual Conference of the Cognitive Science Society, 2988-2994. Presented at the 41st Annual Conference of the Cognitive Science Society, Montreal, Quebec. Austin, TX: Cognitive Science Society. https://doi.org/10.31234/osf.io/xp736

Trecca, F., Tylén, K., Højen, A. \& Christiansen, M.H. (submitted). Danish as a window onto lamguage acquisition and processing. Submitted manuscript.

Tylén, K., Christensen, P., Roepstorff, A., Lund, T., Østergaard, S., \& Donald, M. (2015). Brains striving for coherence: Long-term cumulative plot formation in the default mode network. NeuroImage, 121, 106-114. https://doi.org/10.1016/j.neuroimage.2015.07.047

Yurovsky, D., Case, S., \& Frank, M. C. (2017). Preschoolers Flexibly Adapt to Linguistic Input in a Noisy Channel. Psychological Science, 28(1), 132-140. https://doi.org/10.1177/0956797616668557

Wabersich, D., \& Vandekerckhove, J. (2014). The RWiener Package: an R Package Providing Distribution Functions for the Wiener Diffusion Model.R Journal, 6(1). 
Cross-linguistic differences in categorical perception 


\section{Appendix}

\section{Danish stimuli}

\section{toendt-bias NEAR (FAR)}

Hun har

Hun har

Hun har

Hun har

Hun har

Hun har

Hun har

Hun har

bordbombe et (langt og virkelig fint) vokslys et (ekstremt faretruende) bål et (nyt og temmelig dyrt) pipe et (forsigtigt men vigtigt) håb en (imponerende klar) lampe en (flot og meget uventet) flamme en (særlig betydningsfuld) glød en (overraskende kraftig)

\section{sendt-bias NEAR (FAR)}

Hun har

Hun har

Hun har

Hun har

Hun har

Hun har

Hun har

Hun har et (langt og virkelig fint) brev et (ekstremt faretruende) svar et (nyt og temmelig dyrt) paraply et (forsigtigt men vigtigt) blik en (imponerende klar) mail en (flot og meget uventet) gave en (særlig betydningsfuld) besked en (overraskende kraftig) advarsel

\section{Norwegian stimuli}

tent-bias NEAR (FAR)

Hun har et (langt og virkelig fint) vokslys

Hun har et (ekstremt faretruende) bål

Hun har en (ny og temmelig dyr) pipe

Hun har et (forsiktig men viktig) håp

Hun har en (imponerende klar) lampe

Hun har en (flot og meget uventet) flamme

Hun har en (særlig betydningsfull) glød

Hun har bordbombe en (overraskende kraftig)

\section{sendt-bias NEAR (FAR)}

Hun har Hun har et (langt og virkelig fint) brev

Hun har et (ekstremt faretruende) svar

Hun har

Hun har en (ny og temmelig dyr) paraply et (forsiktig men viktig) blikk en (imponerende klar) mail

Hun har en (flot og meget uventet) gave

Hun har en (særlig betydningsfuld) beskjed

Hun har en (overraskende kraftig) advarsel 